\title{
Морфометричні ознаки Plantago major L. (Plantaginaceae) в різних фітоценозах Шосткинського геоботанічного району Сумської області (Україна)
}

\section{Лариса Пеньковська}

DOI https://doi.org/10.29038/2617-4723-2019-388-4-38-46

Сумський національний аграрний університет, Суми, Україна

Адреса для листування: e-mail: lara_penkovskaya@ukr.net

Отримано: 20.09.19; прийнято до друку: 20.10.19; опубліковано: 27.12.19

Резюме. У складі різних фітоценозів рослини Plantago major L. зазнають значного антропогенного впливу і потребують детального вивчення та розробки заходів щодо збереження та відтворення його популяцій. Питання зміни морфометричних параметрів залежно від типу лісу та густоти насаджень залишаються недостатньо вивченими. Вивчення морфологічних показників P. тајоr дозволяе цілеспрямовано втручатися в процеси росту та розвитку рослин, більш повно використовувати природні властивості рослин, зберігати й відтворювати популяцію та підвищувати її продуктивність.

У цій статті проаналізовано розмірні особливості рослин P. major та визначено їхні морфометричні особливості в різних фітоценозах Шосткинського геоботанічного району Сумської області. Для визначення розмірних параметрів рослин досліджуваного виду ми зробили морфометричний аналіз. 3 цією метою в досліджуваних ценопопуляціях оцінювали ряд статичних метричних та статичних алометричних параметрів.

Рослини P. major виявляють досить різноманітний характер змін величини морфопараметрів відносно угруповання, в якому вони зростають. Формування рослин P. major. в угрупованні Plantagetum (majoris) urticosum (dioici) відрізняються найменшими статичними метричними та алометричними показниками, що вказує на наближеність місцезростань до умов еколого-ценотичного стресу. I навпаки, наявність в угрупованні Pinetum (sylvestris) sorboso (aucuparii)-urticosum (dioici) великорозмірних особин P. major, які виділяються ще й найвищими значеннями статичних метричних та алометричних показників, указує на наближеність цього місцезростання до еколого-ценотичного оптимуму та відношення популяції до процвітаючих.

Виходячи з отриманих результатів, можна сказати, що розмірна структура ценопопуляцій $P$. major суттєво змінюється при переході від одного фітоценозу до іншого. Ця особливість вказує на здатність цього виду до адаптації в різних умовах зростання.

На основі отриманих кількісних та якісних характеристик ценопопуляцій досліджуваного виду ми можемо більш чітко оцінити ресурсний потенціал P. major та запропонувати науково обгрунтовані підходи до раціонального використання наявних запасів цінної лікарської сировини в зоні дослідження.

Ключові слова: ценопопуляція, Plantago major L., морфометричний аналіз, фітоценози.

\section{Morphometric parameters of Plantago major L. (Plantaginaceae) in the conditions of different phytocenoses of the Shostka geobotanical district, Sumy region (Ukraine)}

\section{Larysa Penkovska}

Sumy National Agrarian University, Sumy, Ukraine

Correspondence: e-mail: lara_penkovskaya@ukr.net

Abstract. As a part of the different phytocenoses, Plantago major L. undergoes significant anthropogenic effects and requires detailed study and development of measures for the preservation and reproduction of its 
populations. The issues of changing the morphometric parameters, depending on the forest site type and the stand density, remain poorly studied. The study of morphological parameters P. major allows to interfere purposefully in the processes of growth and development of plants, to use more fully the natural properties of plants, to preserve and reproduce the population and increase its productivity.

In this article analyze the dimensional features P. major plants and to determine their morphometric features in different phytocenoses in Shostka geobotanical district of Sumy region.

To determine the dimensional parameters of plants of the researched species, we made a morphometric analysis. For this purpose, a number of static metric and static alometric parameters were evaluated in the studied cenopopulations.

As a conclusion, we can say that, plants of $P$. major show a rather diverse nature of changes in the magnitude of morphological parameters relative to the group in which they grow. Formation of plants $P$. major in the group Plantagetum (majoris) urticosum (dioici), is characterized by the smallest static metric and alometric parameters indicating the proximity of places to ecological-cenotic stress conditions. Conversely, the presence in the group Pinetum (sylvestris) sorboso (aucuparii)-urticosum (dioici) of large-sized individuals, which are also distinguished by the highest values of a number, static metric and alometric parameters, indicates the proximity of this location to the ecological-cenotic optimum and the relation of the population to the prosperous.

Based on the obtained results, we can say that, the morphometric structure of P. major populations significantly changes during the transition from one phytocenosis to another. This feature indicates the ability of this species to adapt to different growth conditions.

On the basis of the obtained quantitative and qualitative characteristics of the cenopopulations of the researched species, we are able to distinguish more fo estimate the resource potential of $P$. major and to propose scientifically grounded approaches for the rational use of available stocks of valuable medicinal raw materials in the research area.

Key words: cenopopulations, Plantago major L., morphometric analysis, phytocenoses.

\section{ВСТУП}

Одним із джерел отримання лікарських засобів сучасної медицини є лікарські рослини. Фітопрепарати широко застосовуються в медичній практиці і відіграють важливу роль улікарській терапії. Вони належать до багатьох фармакотерапевтичних груп лікарських засобів i часто не мають рівноцінних синтетичних аналогів. Збільшення попиту на лікарські рослинні засоби та біологічно активні добавки в останні десятиліття викликало потребу у збільшенні обсягів заготівлі рослинної сировини $[1,2]$.

Будучи невід'ємною частиною екосистеми, рослинний світ зазнає постійної дії багатьох чинників, але найбільш впливовий 3 них антрепогенний фактор. Так, тривала безконтрольна заготівля сировини дикорослих рослин для використання в різних галузях народного господарства, інтенсифікація експлуатації неурбанізованих територій, осушення земель призвели до катастрофічного зменшення запасів багатьох видів рослин флори України [3, 4].

Протягом останніх років видовий склад лікарських рослин досить різко змінився. Така ситуація спостерігається i на теренах Сумського Полісся, оскільки інтенсивна господарська діяльність веде до виснаження ресурсів лікарських рослин.

Як відомо, однією з важливих характеристик популяцій, структурними одиницями яких $\epsilon$ особини, виступає різноманітність будови та властивостей рослин $[5,6,7]$. Саме тому http://journalbio.eenu.edu.ua питання оцінки розмірних величин рослин Plantago major L., а також визначення їхніх морфометричних особливостей в різних фітоценозах $є$ важливим та актуальним.

Подорожник великий (Plantago major L.) багаторічна трав'яниста рослина родини подорожникових (Plantaginaceae). Лікарська рослина поширена на всій Україні (заготовляють у всіх областях України). Запаси сировини значні, однак поступово зменшуються у зв'язку 3 інтенсивним випасом худоби та збільшенням розораності земель. Офіциналь-ною сировиною є листя і насіння. Листя Plantago major містить полісахариди (20\%), представлені пектиновими речовинами та нейтральними гліканами. Наявні також маніт, сорбіт, алантоїн, іридоїди (аукубін та каталпол), стероїди, флавоноїди (похідні лютеоліну, кверцетину, апігеніну та ін.), дубильні речовини. Листя й трава містять каротиноїди, вітаміни С, холін, аденін, сапоніни, сліди алкалоїдів, слиз, оксикоричні кислоти (хлорогенова i неохлорогенова), фактор Т (бере участь у процесі згортання крові). У насінні $є$ значна кількість слизу, жирна олія, аукубін, олеанолова кислота, стероїдні сапоніни та вуглеводи.

Листки P.major у вигляді препаратів виявляють різнобічну терапевтичну дію: протизапальну, секреторну, знеболювальну, кровоспинну, ранозагоювальну, бактеріостатичну, седативну та протиалергічну [8].

На сьогодні в науковій літературі накопичений значний обсяг інформації про поширення та стан популяцій $P$. major. Протягом 25 років 3 
Морфометричні ознаки Plantago major L. (Plantaginaceae) в різних фітоценозах Шосткинського геоботанічного району Сумської області (Украӥна)

P. major пов'язана різнобічна програма досліджень в Данії і Голландії [9].

У Росії проводилися популяційні дослідження P. major, де велика увага була приділена демографічним аспектам життя популяцій [10]. Дослідження показали, що в умовах декількох регіонів Росії в природних ценопопуляціях доказана чітка позитивна кореляція фенотипових змін, як вегетативних, так i генеративних органів у всіх рослин генеративного періоду [11]. В Україні цей вид вивчали Т. В. Хортецька, Г. П. Смойловська, які проводили мікроскопічні дослідження P. major [12].

Мета статті - оцінити розмірні величини рослин P. major та визначити їхні морфометричні особливості в різних лісових фіто ценоззах Шосткинського геоботанічного району.

Завдання: визначити величини провідних статичних метричних й алометричних морфопараметрів у рослин $P$. major у лісових фітоценозах, які $\epsilon$ типовими для регіону; проаналізувати характер зміни значень морфопараметрів за досліджуваними угрупованнями.

\section{МАТЕРІАЛИ Й МЕТОДИ ДОСЛІДЖЕНЬ}

Дослідженнями було охоплено ценопопуляції Plantago major L. із дев'яти різних угруповань:

1. Pineto (sylvestris) - Aceretum (platanoiditis) chelidoniosum (majus) - П1;

2. Pineto (sylvestris) - Aceretum (platanoiditis) achilleosum (millefoluim) - П2;

3. Pinetum (sylvestris) coryloso (avellanae)bromopsiosum (inermis) - П3;

4. Pinetum (sylvestris) sorboso (aucuparii)urticosum (dioici) - П4;

5. Quercetum (roboris) coryloso (avellanae)taraxacosum (officinale) - П5;

6. Tilietum (cordatae) elytrigioso (repenae)plantagosum (major) - П6;

7. Setarietum (pumila)plantagosum (major) - П7;

8. Plantagetum (majoris) capsellosum (bursapastoris) - П8;

9. Plantagetum (majoris) urticosum (dioici) $-\Pi 9$

Для визначення розмірних параметрів рослин досліджуваних видів, та установлення деяких інших видів структури ценопопуляцій було використано морфометричний аналіз [13].

Виходячи 3 загальновизначених підходів морфометричного аналізу 3 числа статичних метричних показників визначали висоту рослини $(\mathrm{H}, \mathrm{cm})$, діаметр головного пагона $(\mathrm{D}$, мм), кількість листків (NL, шт.), а також кількість генеративних пагонів (Bgen, шт.), загальну масу рослини (W, г), а також масу усіх листків (WL, г) й одного листка (W1L, г), загальну масу генеративних органів $(\mathrm{Wg}$, г) та загальну площу листкової поверхні $\left(\mathrm{A}, \mathrm{cm}^{2}\right)$.

Зі статичних алометричних показників оцінювали співвідношення між площею листкової поверхні та фітомасою рослин $\left(\mathrm{LAR}=\mathrm{A} / \mathrm{W}, \mathrm{cm}^{2} / \Gamma\right)$, фотосинтетичне зусилля $(\mathrm{LWR}=\mathrm{WL} / \mathrm{W}, \Gamma / \Gamma)$, відносний приріст головного пагона $(\mathrm{HWR}=\mathrm{H} / \mathrm{W}, \mathrm{cm} / \Gamma)$, відношення висоти рослини до діаметра стебла (HDR=H/D, см/см), відношення площі листя до діаметра стебла $\left(\mathrm{ADR}=\mathrm{A} / \mathrm{D}, \mathrm{cm}^{2} / \mathrm{Mm}\right)$; площу листків на одиницю фітомаси листків (SLA= A/WL, $\left.\mathrm{cm}^{2} / \Gamma\right)$ та репродуктивне зусилля: $(\mathrm{RE} 1=(\mathrm{Wg} / \mathrm{W}) \mathrm{x}$ $100 \%, \mathrm{RE} 2=(\mathrm{Wg} / \mathrm{A}) \times 100 \%, \%)$.

Для оцінки статистичної достовірності отриманих кількісних даних та їхнього узагальнення застосовували точкове, інтервальне оцінювання та дисперсійний аналіз [14]. Усе це забезпечувалось використанням статистичних комп'ютерних пакетів STATISTICA та PAST.

\section{РЕЗУЛЬТАТИ Й ОБГОВОРЕННЯ}

Досліджувані популяції P. major статистично достовірно (при $\mathrm{p}<0,05$ ) відрізняються між собою за значеннями усіх досліджуваних розмірних величин (17 3 17). Результати оцінки розмірних величин у рослин P. major представлено в табл. 1 і табл. 2.

Кожному 3 морфопараметрів притаманні свої специфічні особливості щодо змін величин при переході від одної ценопопуляції до іншої (рис. 1). При цьому найбільші значення двох (загальна маса рослини ( $\mathrm{W}=24,81+1,068$ г), загальна маса генеративних органів $(\mathrm{Wg}=7,01+0,314 \quad$ г) $)$ із дев'яти статичних метричних показників, які були оцінені у P. major, зарєстровано в популяції Pinetum (sylvestris) sorboso (aucuparii)-urticosum (dioici). Рослини 3 цього угруповання вирізняються найбільшими величинами двох із восьми оцінених статичних алометричних показників, таких як: відношення площі листків до діаметра стебла $\left(\mathrm{ADR}=327,16+28,795 \mathrm{~cm}^{2} / \mathrm{MM}\right)$; фотосинтетичне зусилля $(\mathrm{LWR}=0,44+0,014$ г/г).

Натомість у ценопопуляції 3 угруповання Plantagetum (majoris) urticosum (dioici), навпаки, зареєстровано найменші значення шести статичних показників (висота рослини $(\mathrm{H}=21,08+0,360 \mathrm{~cm})$, кількість генеративних 
Науковий вісник Східноєвропейського національного університету імені Лесі Українки. Серія: Біологічні науки, 2019, 4 (388)

пагонів (Bgen=1,80+0,081 шт.), маса одного листка (W1L=1,06+0,029 г), загальна маса рослини (W=13,37+0,522 г), кількість листків $(\mathrm{NL}=4,68+0,125$ шт.) та загальна площа листкової поверхні $\left.\left(\mathrm{A}=144,56+3,889 \mathrm{~cm}^{2}\right)\right)$ i трьох алометричних показників (відношення площі листків до діаметра стебла (ADR= $\left.138,62+4,611 \mathrm{~cm}^{2} / \mathrm{MM}\right)$, показник репродуктивного зусилля (RE2 $=1,35+0,062 \%)$ та відношення висоти рослини до діаметра стебла $(\mathrm{HDR}=20,28+0,648 \mathrm{~cm} / \mathrm{cm})$ ).

Окрім того, відмінною особливістю рослин P. major iз угруповання Plantagetum (majoris) capsellosum (bursa-pastoris) є те, що вони мають найбільші статичні морфопараметри 3 таких величин, як: маса одного листка $(\mathrm{W} 1 \mathrm{~L}=2,00+0,068$ г), діаметр головного пагона $(\mathrm{D}=1,09+0,061$ мм), загальна площа листкової поверхні $\left(A=197,65+8,787 \mathrm{~cm}^{2}\right)$.

В ценопопуляції з угруповання Quercetum (roboris) coryloso (avellanae)-taraxacosum (officinale) зареєстровано найменші значення трьох статичних показників, таких як маса усіх листків (WL=2,49+0,167 г), діаметр головного пагона $(\mathrm{D}=0,47+0,010 \mathrm{Mм}), \quad$ загальна маса генеративних органів $(\mathrm{Wg}=7,01+0,314$ г), та найбільшим значенням одного алометричного показника відносний приріст головного пагона $(\mathrm{HWR}=2,49+0,169 \mathrm{~cm} / г)$.

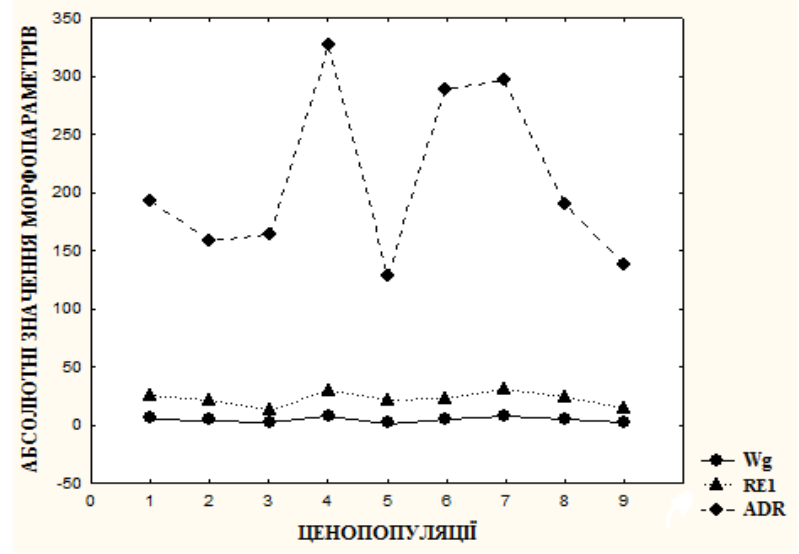

Рис. 1. Зміна величин середніх значень морфопараметрів у рослин иеенопопулячій

Plantago major за досліджуваними місцезростаннями (нумерація угруповань відповідає наведеній у тексті)

\section{Морфометричні параметри рослин Plantago major в умовах лісових угруповань}

Таблиияя 1

\begin{tabular}{|c|c|c|c|c|c|c|c|}
\hline \multirow{3}{*}{$\begin{array}{c}\text { Морфо- } \\
\text { параметри }\end{array}$} & \multicolumn{6}{|c|}{ Угруповання } & \multirow{3}{*}{$\begin{array}{c}\text { Значення } \\
\text { довірчого } \\
\text { рівня, p }\end{array}$} \\
\hline & $\begin{array}{c}\text { Pineto } \\
\text { (sylvestris)- } \\
\text { Aceretum } \\
\text { (platanoiditis) } \\
\text { chelidoniosum } \\
\text { (majus) } \\
\Pi 1\end{array}$ & \begin{tabular}{|c|} 
Pineto \\
(sylvestris)- \\
Aceretum \\
(platanoiditis) \\
achilleosum \\
(millefoluim) \\
$\Pi 2$ \\
\end{tabular} & $\begin{array}{c}\text { Pinetum } \\
\text { (sylvestris) } \\
\text { coryloso } \\
\text { (avellanae)- } \\
\text { bromopsiosum } \\
\text { (inermis) } \\
\Pi 3\end{array}$ & $\begin{array}{c}\text { Pinetum } \\
\text { (sylvestris) } \\
\text { sorboso } \\
\text { (aucuparii)- } \\
\text { urticosum } \\
\text { (dioici) } \\
\text { П4 }\end{array}$ & $\begin{array}{c}\text { Quercetum } \\
\text { (roboris) } \\
\text { coryloso } \\
\text { (avellanae)- } \\
\text { taraxacosum } \\
\text { (officinale) } \\
\text { П5 }\end{array}$ & \begin{tabular}{|c|} 
Tilietum \\
(cordatae) \\
elytrigioso \\
(repenae)- \\
plantagosum \\
(major) \\
$\Pi 6$ \\
\end{tabular} & \\
\hline & $\overline{\mathrm{X}} \pm S_{\bar{x}}$ & $\overline{\mathrm{X}} \pm S_{\bar{x}}$ & $\overline{\mathrm{X}} \pm S_{\bar{x}}$ & $\overline{\mathrm{X}} \pm S_{\bar{x}}$ & $\overline{\mathrm{X}} \pm S_{\bar{x}}$ & $\overline{\mathrm{X}} \pm S_{\bar{x}}$ & \\
\hline \multicolumn{8}{|c|}{ статичні метричні морфопараметри } \\
\hline $\mathrm{H}$ & $39,72+0,347$ & $25,57 \pm 0,663$ & $227,15+0,6$ & $36,54 \pm 0,952$ & $15,92+0,63$ & $34,62+0,9$ & $0,000 *$ \\
\hline W1L & $1,89 \pm 0,053$ & $1,54 \pm 0,0618$ & $1,77 \pm 0,054$ & $1,92 \pm 0,070$ & $0,96 \pm 0,041$ & $1,65 \pm 0,08$ & $0,000 *$ \\
\hline WL & $8,55 \pm 0,345$ & $6,6,61 \pm 0,2$ & $6,98 \pm 0,116$ & $10,98 \pm 0,487$ & $2,49 \pm 0,167$ & $7,54 \pm 0,227$ & \\
\hline $\mathrm{D}$ & $0,92+0,034$ & $1,01 \pm 0,035$ & $1,06+0,046$ & $0,80 \pm 0,040$ & $0,47 \pm 0,010$ & $0,65 \pm 0,036$ & $0,000 *$ \\
\hline Bgen & $3,82 \pm 0,086$ & $1,96 \pm 0,095$ & $2,53 \pm 0,138$ & $3,95 \pm 0,191$ & $2,57 \pm 0,289$ & $3,29 \pm 0,212$ & $0 *$ \\
\hline A & $170,62 \pm 6,971$ & $1157,67 \pm 3,2$ & $161,46 \pm 2,49$ & $245,81 \pm 15,3$ & $160,33 \pm 3,92$ & $180, \overline{6} 6 \pm 7,3$ & $0,000 *$ \\
\hline $\mathrm{W}$ & $20,93 \pm 0,698$ & $16,88 \pm 0,337$ & $19,61 \pm 0,612$ & $24,81 \pm 1,068$ & $16,88 \pm 0,53$ & $23,55+1,46$ & \\
\hline Wgen & $5,41 \pm 0,290$ & $2,24 \pm 0,124$ & $4,04 \pm 0,1558$ & $7,01 \pm 0,314$ & $1,342 \pm 0,116$ & $5,05 \pm 0,309$ & $0,000 *$ \\
\hline NL & $7,06 \pm 0,325$ & $5,53 \pm 0,1665$ & $6,00 \pm 0,175$ & $7,04 \pm 0,304$ & $6,04 \pm 0,334$ & $7,41 \pm 0,312$ & $0,000 *$ \\
\hline \multicolumn{8}{|c|}{ статичні алометричні морфопараметри } \\
\hline $\mathrm{R}$ & $39 \pm 0,432$ & $9,47 \pm 0,329$ & $8,40 \pm 0,261$ & $10,42 \pm 0,848$ & $9,11 \pm 0,491$ & $8,44 \pm 0,756$ & $00 *$ \\
\hline LWR & $0,41 \pm 0,018$ & $0,39 \pm 0,013$ & $0,36 \pm 0,013$ & $0,44 \pm 0,014$ & $0,38 \pm 0,027$ & $0,35 \pm 0,027$ & $0,004 *$ \\
\hline HWR & $1,95 \pm 0,069$ & $1,52 \pm 0,041$ & $1,41+0,053$ & $1,52 \pm 0,075$ & $2,49 \pm 0,169$ & $1,61 \pm 0,125$ & $0,000 *$ \\
\hline HDR & $445,51 \pm 2,625$ & $25,98 \pm 0,836$ & $27,09 \pm 1,935$ & $47,62 \pm 2,154$ & $33,79 \pm 1,18$ & $55,06 \pm 2,09$ & $0,000 *$ \\
\hline RE1 & $25,80 \pm 1,088$ & $13,32 \pm 0,726$ & $20,90 \pm 0,869$ & $28,81 \pm 1,305$ & $20,78 \pm 1,69$ & $22,09 \pm 1,37$ & $0,000 *$ \\
\hline RE2 & $3,29+0,196$ & $1,45 \pm 0,090$ & $2,52 \pm 0,108$ & $3,27 \pm 0,373$ & $2,34 \pm 0,179$ & $2,94 \pm 0,215$ & $0,000 *$ \\
\hline SLA & $220,48 \pm 0,893$ & $24,56 \pm 1,029$ & $23,27 \pm 0,505$ & $24,03 \pm 2,230$ & $25,47 \pm 1,3$ & $24,86 \pm 1,702$ & $0,000 *$ \\
\hline ADR & $193,60 \pm 12,056$ & $164,00 \pm 8,698$ & $159,50 \pm 8,495$ & $327,16 \pm 28,795$ & $128,83 \pm 8,42$ & $288,23 \pm 14,6$ & $0,000 *$ \\
\hline
\end{tabular}


Морфометричні ознаки Plantago major L. (Plantaginaceae) в різних фітоиенозах Шосткинського геоботанічного району Сумської області (Украӥна)

Табличя 2

Морфометричні параметри рослин Plantago major в умовах лучних угруповань

\begin{tabular}{|c|c|c|c|c|}
\hline \multirow{3}{*}{$\begin{array}{c}\text { Морфо-- } \\
\text { параметри }\end{array}$} & \multicolumn{3}{|c|}{ Угруповання } & \multirow{3}{*}{$\begin{array}{l}\text { Значення } \\
\text { довірчого } \\
\text { рівня, p }\end{array}$} \\
\hline & $\begin{array}{c}\text { Setarietum (pumila) } \\
\text { plantagosum (major) } \\
\Pi 77\end{array}$ & $\begin{array}{c}\text { Plantagetum (majoris) } \\
\text { capsellosum } \\
\text { (bursa-pastoris) } \\
\Pi 8 \\
\end{array}$ & $\begin{array}{c}\text { Plantagetum (majoris) } \\
\text { urticosum (dioici) } \\
\Pi 9 \\
\end{array}$ & \\
\hline & $\overline{\mathrm{X}} \pm S_{\bar{x}}$ & $\overline{\mathrm{X}} \pm S_{\bar{x}}$ & $\overline{\mathrm{X}} \pm S_{\bar{x}}$ & \\
\hline \multicolumn{5}{|c|}{ статичні метричні морфопараметри } \\
\hline $\mathrm{H}$ & $33,60 \pm 1,438$ & $32,70 \pm 0,808$ & $21,08 \pm 0,360$ & $0,000 *$ \\
\hline W1L & $1,92 \pm 0,067$ & $2,00 \pm 0,068$ & $1,06 \pm 0,029$ & $0,000^{*}$ \\
\hline WL & $10,35 \pm 0,705$ & $8,51 \pm 0,471$ & $5,17 \pm 0,086$ & $0,000^{*}$ \\
\hline $\mathrm{D}$ & $0,69 \pm 0,0467$ & $1,09+0,061$ & $1,06 \pm 0,034$ & $0,000 *$ \\
\hline Bgen & $3,45 \pm 0,198$ & $3,25 \pm 0,160$ & $1,80 \pm 0,081$ & $0,000^{*}$ \\
\hline $\mathrm{A}$ & $193,15 \pm 11,14$ & $197,65 \pm 8,787$ & $144,56 \pm 3,889$ & $0,000^{*}$ \\
\hline $\mathrm{W}$ & $23,25 \pm 1,065$ & $20,38 \pm 0,706$ & $13,37 \pm 0,522$ & $0,000^{*}$ \\
\hline Wgen & $7,00 \pm 0,340$ & $4,93 \pm 0,293$ & $1,94 \pm 0,093$ & $0,000 *$ \\
\hline NL & $6,60 \pm 0,335$ & $6,60 \pm 0,265$ & $4,68 \pm 0,125$ & $0,000^{*}$ \\
\hline \multicolumn{5}{|c|}{ статичні алометричні морфопараметри } \\
\hline LAR & $8,40 \pm 0,449$ & $9,74 \pm 0,344$ & $11,04 \pm 0,373$ & $0,000^{*}$ \\
\hline LWR & $0,44 \pm 0,018$ & $0,41 \pm 0,017$ & $0,39 \pm 0,013$ & $0,005^{*}$ \\
\hline HWR & $1,48 \pm 0,075$ & $1,62 \pm 0,054$ & $1,62 \pm 0,054$ & $0,000^{*}$ \\
\hline HDR & $50,09 \pm 1,706$ & $31,37 \pm 1,477$ & $20,28 \pm 0,648$ & $0,000 *$ \\
\hline RE1 & $30,57 \pm 1,389$ & $24,00 \pm 0,869$ & $14,76 \pm 0,709$ & $0,000^{*}$ \\
\hline RE2 & $3,84 \pm 0,295$ & $2,56 \pm 0,172$ & $1,35 \pm 0,062$ & $0,000^{*}$ \\
\hline SLA & $20,36 \pm 1,991$ & $24,23 \pm 1,402$ & $27,97 \pm 0,694$ & $0,002 *$ \\
\hline ADR & $297,06 \pm 22,933$ & $190,20 \pm 11,328$ & $138,62 \pm 4,611$ & $0,000 *$ \\
\hline
\end{tabular}

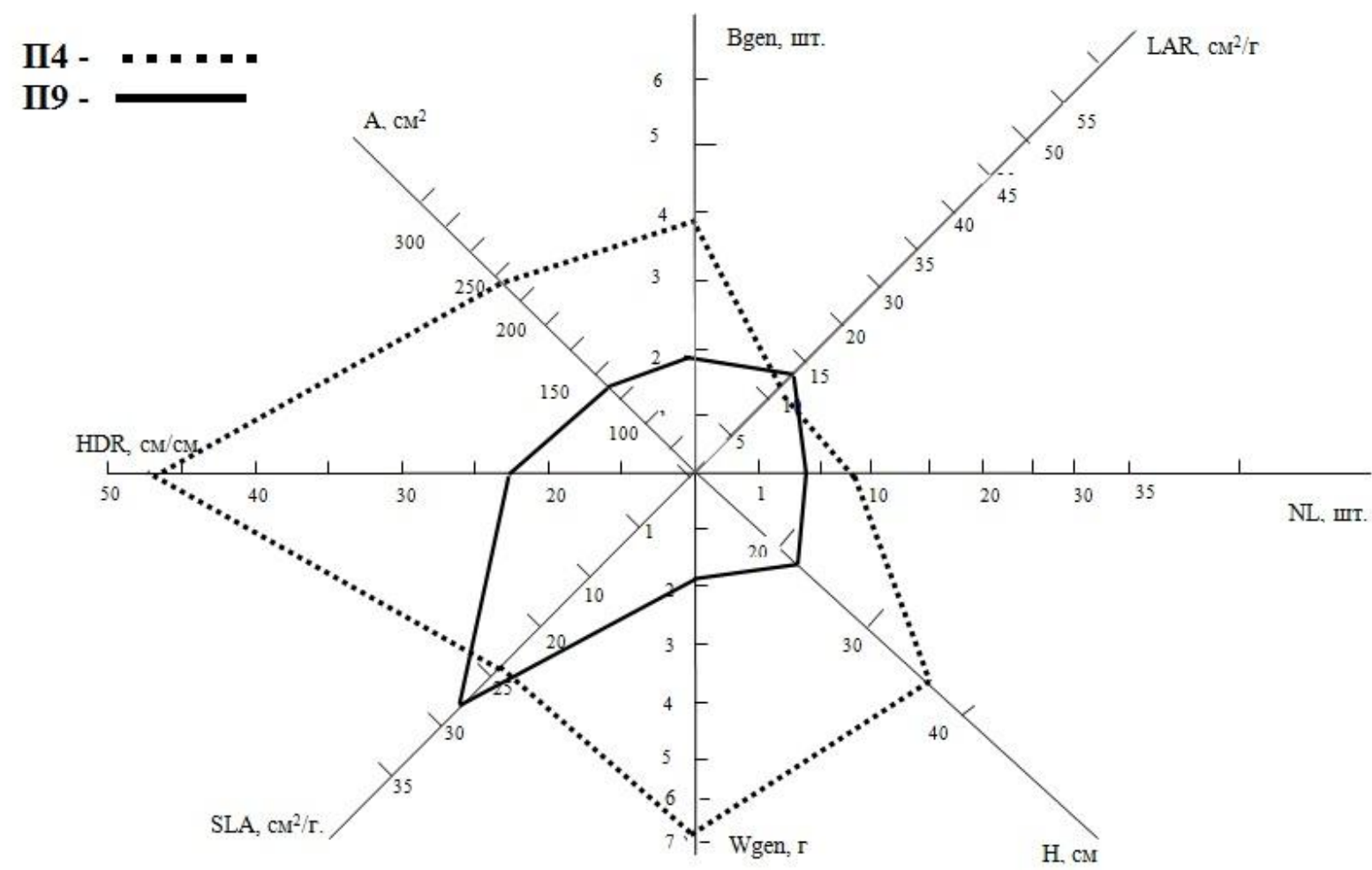

Рис. 2. Морфограма рослин двох ценопопуляиій Plantago тајоr, сформованих у різних фітоценозах (нумераиія угруповань відповідає наведеній у тексті) 
Отже, розмірна структура ценопопуляцій $P$. major суттєво змінюється при переході від одного фітоценозу до іншого. Ця особливість вказує на здатність цього виду до адаптації в різних умовах зростання (рис. 2).

\section{ВИСНОВКИ}

Рослини P.major виявляють досить різноманітний характер змін величини морфопараметрів відносно угруповання, в якому вони зростають.

Формування в угрупованні Plantagetum (majoris) urticosum (dioici) рослин P. major, що відрізняються найменшими статичними метричними та алометричними показниками, вказує на наближеність місцезростань до умов еколого-ценотичного стресу. Відносно оцінки якості популяції по частковій участі особин різного розміру в складі ценопопуляцій, можна сказати, що рослини 3 цієї популяції характеризуються переважанням найнижчих показників досліджуваних морфопараметрів, що також вказує на депресивність цієї популяції .

I навпаки наявність в угрупованні Pinetum (sylvestris) sorboso (aucuparii)-urticosum (dioici) особин $P$. major, що вирізняються найвищими значеннями низки як, статичних метричних так алометричних показників, вказує на наближеність цього місцезростання до екологоценотичного оптимуму та відношення популяції до процвітаючих.

Зважаючи на виявлені особливості розмірної структури $P$. major на території Сумської області, необхідний подальший моніторинг цього виду, що дасть змогу розробити дієві методи збереження виду та прогнозування розвитку популяцій відносно постійних змін навколишнього середовища.

\section{ЛIТЕРАТУРА}

1. Мінарченко, В. М., Тимченко, І. А. Атлас лікарських рослин Украӥни (хронологія, ресурси та охорона). Фітосоціоцентр: Київ, 2002; с 172.
2. Лихочвор, В. В., Борисюк, В. С., Дубковецький, С. В. Лікарські рослини. Українські технології: Львів:, 2003; с 265.

3. Кисличенко, В. С., Ленчик, Л. В., Новосел, О. М., Кузнєцова, В. Ю. Ресурсознавство лікарських рослин. Посібник для студентів спеціальності «Фармаиія». НФаУ: Харків, 2015; с 136.

4. Скляр, В. Г. Популяционный мониторинг. Популяции редких видов растений: теоритические осеовы и методика изучения. Університетська книга: Суми, 2013, с 326-334.

5. Злобин, Ю. А. Популяционная экология растений: современное состояние, точки роста. Університетська книга: Суми, 2009; с 263.

6. Скляр, В. Г. Внутрішньопопуляційна структура та методика iї вивчення у деревних лісоутворюючих видів. Чорноморський ботанічний журнал; 2013, 3, с 316-329.

7. Skliar, V., Sherstuk, M. Size structure of phytopopulations and its quantitative evaluation. Eureka: Life Sciences; 2016, 1, p 9-16.

8. Ивашин, Ю.Д. Лекарственные растения Украины. «Урожай»: Киев, 1971; с 352.

9. Van der Aart, P. J. M. Demographic, genetic and ecophysiological variation in Plantago major and P.lanceolata in relation to vegetation type. The population structure of vegetation. J.White (ed.). Dordrecht, Boston, Lancaster, 1985; 3, p 441-462.

10. Жукова, Л. А., Комаров, А. С. Поливариантность онтогенеза и динамика ценопопуляций растений. Журнал общей биологии; 1990, 4, с 450-461.

11. Жукова, Л. А., Заугольнова, Л. Б., Смирнова, О. В. Динамика ценопопуляиий растений (основные понятия и структура). Наука: Москва, 1985; c 187-196.

12. Хортецька, Т. В., Смойловська, Г. П. Мікроскопічні дослідження подорожника великого та подорожника середнього при ідентифікації лікарської рослинної сировини. Актуальні питання фармачевтичної $і$ медичної науки та практики; 2017, 1, c 54-59.

13. Злобін, Ю. А., Скляр, В. Г., Бондарєва, Л. М., Кирильчук, К. С. Концепція морфометрії у сучасній ботаніці. Чорноморський ботанічний журнал; 2009, 1, с 5-22.

14. Злобін, Ю. А., Скляр, В. Г. Комп'ютерні методи в сільському господарстві та біології. Навчальний посібник. Університетська книга: Суми, 2000; c 203. 